\title{
Marjan Kozina: Majda
}

\author{
Borut Smrekar \\ Slovensko ljudsko gledališče Celje \\ Celje City Theatre
}

\section{Nastanek}

Potem ko sem l. 32 zaključil mojstrsko šolo v Pragi (pri Suku), celih sedem let nisem skomponiral skoraj ničesar ... To se je hipoma spremenilo, čim sem l. 39 prišel v Beograd. Iznenada so se odprla neka tajna vratca in naenkrat sem občutil, da imam nekaj povedati in to osebno na samo moj način. ${ }^{.}$

Tako je leta 1963 Marjan Kozina opisoval prehojeno skladateljsko pot. Že pred tem je izjavil, da »nekaj čisto brezpomembnih in slabih priložnostnih del iz tega časa sploh ne šteje«. ${ }^{2}$ Med ta »brezpomembna in slaba priložnostna« dela sodi tudi celovečerna opereta Majda, premierno uprizorjena 24. novembra $1935 \mathrm{v}$ mariborskem Narodnem gledališču.

Vprašanje je, ali je bil takšen skladateljev odnos do njegovega odrskega prvenca iskren ali pa gre le za prirejeno izjavo, morda zaradi stigme, s katero je bil v drugi polovici dvajsetega stoletja zaznamovan operetni žanr na Slovenskem. Kozina je bil sicer vse prej kot verodostojen pričevalec, a kljub temu je malo verjetno, da bi Majdo »pozabil«, o čemer priča tudi njegov kasnejši zapis: „Natihoma povedano, vesel sem je še danes, ko sem našel že čisto druga pota. $\aleph^{3}$

1 Pismo Peru Bingulcu ob pripravah na uprizoritev »Ekvinokcija«v Novem Sadu, Piran, 12. oktober 1963. Prepis Jurija Kozine (pri avtorju).

2 Ciril Cvetko, Marjan Kozina (Ljubljana: Partizanska knjiga, 1983), 103.

3 Ibid., 104. 
Kozinova leta po zaključku študija zaznamujejo obupna prizadevanja za uveljavitev in želja po uspehu. Operetni žanr mu ni bil tuj in verjetno je računal, da bo $z$ opereto najlažje prodrl. Na to kažejo številna prizadevanja za postavitev Majde na druge odre, pa tudi pisanje druge operete "Dekle z Jadrana « ${ }^{4}$ za tujega naročnika, ki je zaradi spleta okoliščin ostala nedokončana.

O nastanku Majde naletimo na dve različni pričevanji, podani sočasno. ${ }^{6}$ Kozina je pred premiero navedel, da je bila Majda

prvotno zamišljena kot radiofonska opereta, ki jo je podajala ljubljanska radijska postaja. Izvajala se je menda $v$ mesecu maju ali juniju tega leta. Ker je dobro uspela, sem se s svojimi prijatelji odločil, da jo prikrojim in priredim za odrsko uporabo. Bilo jo je treba samo še glasbeno razširiti ter oskrbeti besedilo in drugo potrebno kakor npr. za balet, itd. Z Delakom, ki se je spravil na Knafličevo tridejanko 'Kmečki teater', sva se lotila te naloge, ki sva jo po večmesečnem temeljitem pripravljanju zaključila. Tako je nastala 'Majda'.

Pričevanje režiserja predstave Ferda Delaka, objavljeno prav tako pred premiero, se precej razlikuje. Josip Fran Knaflič naj bi se leta 1933 v mariborskem gledališču dogovoril za uprizoritev svoje veseloigre »Kmečki teater «, posvečene spominu Frana Milčinskega. Za režiserja je bil določen Delak, kateremu je Knaflič izročil tekst. Upravnik gledališča Brenčič je svetoval poživitev dela z glasbenimi točkami in zato je Delak pritegnil k uprizoritvi Kozino. Ob njunem sodelovanju pri postavitvi veseloigre se je začela luščiti ideja o opereti. Zato je Delak Knafličev tekst nekoliko priredil in povabil k sodelovanju še Mirka Jelačina, da je

skoval vrsto rim na vesele in sentimentalne verze, in jih kot operetni poet podložil Kozinovi muziki. Med delom za odrsko opereto je Igor Grdina, »Kozinovo Dekle z Jadrana«, v Marjan Kozina: 2. mednarodni simpozij o Marjanu kozini ob 1oo-letnici rojstva, ur. Primož Kuret (Novo mesto: Glasbena šola Marjana Kozine, 2007), 38-49. kom kot s Kozino. Oba pripovedujeta o nastanku Majde. Intervju s Kozino je bil ponatisnjen v Jutru 24. 11. 1935. www.dlib.si/?URN=URN:NBN:SI:doc-QNTN2ZDD. 
nastajala radijska opereta, $k i$ je bila lani izvajana trikrat $v$ studiu ljubljanske radiofonske postaje. ${ }^{8}$

Obe nasprotujoči si zgodbi sta bili objavljeni $\mathrm{v}$ isti številki mariborskega Večernika. ${ }^{9}$ Delakova zgodba o sočasnem nastanku Majde kot gledališke in radiofonske operete je dosti bolj verjetna. Poleg že omenjene Kozinove nezanesljivosti pri pričevanju govori v prid Delaku tudi časovni potek. Če bi verjeli Kozini, bi morala z Delakom v štirih ali petih mesecih razširiti razmeroma skromno radijsko različico $\mathrm{v}$ opereto. Kozina bi tako moral na novo skomponirati dobršen del nove glasbe, že napisano glasbo pa ponovno orkestrirati, ker je bila $v$ radijski različici uporabljena druga inštrumentalna zasedba kot $v$ gledališki. Potem je potrebna še izdelava orkestrskega in zborovskega materiala, študij itd., za kaj takega pa je bilo malo časa in Kozina ni ravno slovel po hitrosti pri skladanju. So pa Majdo na radiju verjetno predvajali v maju ali juniju 1935 in ne 1934, kot je izjavil Delak, kar izhaja iz Kozinovega pisma domačim $\mathrm{z}$ dne 4 . marca $1935 .{ }^{10}$ Se je pa Kozina še $\mathrm{v}$ mesecu oktobru 1935 ubadal z izdelavo orkestrskega materiala, zborovskimi parti in podobnim. ${ }^{\text {II }}$

Od prvotnega dela so se ohranili rokopisna partitura ${ }^{\mathrm{I} 2}$ in prepis klavirskega izvlečka, ${ }^{13}$ ki ju je po naključju našel in rešil dr. Primož Kuret ${ }^{14}$ ter orkestrski material radijske različice. Od izvirnega libreta je ostalo le nekaj fragmentov. Zato je za potrebe koncertne izvedbe Majde leta 1999 Igor Grdina napisal nov libreto, primeren tudi za gledališko uprizoritev. ${ }^{\text {I5 }}$

Ob razčlembi dela se zastavlja vprašanje, kaj pravzaprav je Majda danes. Upoštevaje značilnosti operetne zvrsti, bi bilo treba vsekakor presoja-

8 F. Delak, »Majda, ti moja sreča vsa ... Pred premiero v mariborskem Narodnem gledališču«. Mariborski Večernik »Jutra" 16, št. 267 (23. november 1935): 6, http://www. dlib.si/?URN=URN:NBN:SI:doc-W9CCVRPE.

9 Ibid.

10 Grdina, »Kozinovo Dekle z Jadrana«, 39.

11 Ibid., 41.

12 Partitura - čistopis - je rokopis skladatelja. V njej so naknadno vnesene orkestracijske in druge retuše, nekatere scenske oznake in napotki. Besedilo je vpisano le mestoma, večinoma kot iztočnice. Partitura je bila očitno v uporabi in je Kozina verjetno iz nje dirigiral predstave.

13 Klavirski izvleček je kopija originalnega izvlečka z vtipkanim nemškim besedilom.

14 "Marjan Kozina: Majda, koncertna izvedba operete«, RTV Slovenija, https://4d. rtvslo.si/arhiv/koncerti-kulturno-umetniski-program/174556603.

15 Igor Grdina, »Majda, opereta v treh dejanjih«, v Marjan Kozina, 1907-1966: Mednarodni simpozij o Marjanu Kozini ob koncertni izvedbi operete Majda, ur. Primož Kuret (Novo mesto: Glasbena šola Marjana Kozine, 2002), 139-58. 
ti delo kot celoto, torej tekst, glasbo in tudi kontekst nastanka in izvedbe. V konkretnem primeru se srečujemo $\mathrm{z}$ dvema različicama. Prva je »fragmentarna«, ker je ohranjen le glasbeni del, druga je »celovita" prenova (ne rekonstrukcija prvotne), vendar brez skladateljevega poznavanja teksta. Obe različici povezuje glasba, ki ji kaže nameniti največ pozornosti.

\section{Majda $^{16}$}

\section{Splošni podatki}

Majda je opereta v treh dejanjih. Od prvotnega dela je ohranjena le glasba in nekaj kratkih fragmentov besedila. $\mathrm{V}$ drugi različici je na Kozinovo glasbo in po motivih Knafliča napisal nov libreto Igor Grdina.

\section{Prvotna različica}

Libreto: veseloigra Josipa Frana Knafliča »Kmečki teater« v priredbi Ferda Delaka

Besedila pesmi: Mirko Jelačin

Nastopajoče osebe: Romantična dama; Župan; Majda, njegova hči; Gospod direktor; Janko Rešetar, časnikar; Žanek, športnik; Nande; Špelca, pastirica; Šepav možic; Stara Ženica; I. novinar; II. Novinar; Novinarka; Filmski operater; Napovedovalec radijske postaje; Fotograf; Spremljevalka romantične dame; Potni maršal romantične dame; letoviščarji, turisti, kmetje, igralci »Kmečkega teatra «.

Godi se v slovenskem letovišču. ${ }^{17}$

Vsebina (izvirne operete):

Gospod direktor pripravlja z združenimi vaškimi močmi predstavo, kjer sodeluje vse od župana pa do zadnjega vaškega kozla. Glavni vlogi naj igrata županova Majda in njen fant Nande. Majdin stric, časnikar Rešetar s svojo časnikarsko spretnostjo doseže njuno zve-

16 Uporabljeni glasbeni viri so glasbeni material, ki ga hrani Zgodovinski arhiv Ljubljana, Enota za Dolenjsko in Belo krajino v Novem mestu in sicer: rokopisna partitura, partitura v redakciji Zdravka Hribarja, klavirski izvleček ter izvedbeni material radijske različice.

17 Podatki so povzeti z gledališkega plakata. 
zo. Vzporedno s to osnovo so postavljene na oder še nekatere običajne druge dvojice. ${ }^{18}$

\section{Nova različica}

\section{Libreto: Igor Grdina}

Nastopajoče osebe: Majda Kralj, brezprimerno lepa mladenka, stara kakih dvajset let; Peter Bežek, njen fant; Lojze Malovrh, zajeten gospod okoli Abrahama; Ferdo Kurnik, vdovec, direktor hotela, zagnan 'rodoljub z dežele', vsekakor krepak možak; Špelca, županova hčerka, zelo živahna gospodična; Žan Prunk, njen oboževalec, športnik, motorist itd., lokalni prvak v deseteroboju; Frančiška Ržen, romantična dama; Dr. Aleš Zgaga, znamenit časnikar in navdušen lovec, $\mathrm{v}$ srednjih letih, nekoliko dekadentnega izgleda.

Godi se na slovenskem podeželju okoli leta 1930.

Vsebina (nove različice): Na slovensko podeželje prodira turizem. Ker si vaščani močno prizadevajo privabiti čim več gostov, popestrijo turistično ponudbo z izvedbo srednjeveške drame lokalnega Shakespeara in režiserja $\mathrm{v}$ izvedbi vaškega gledališča, v katerem sodelujejo vsi. Glavno vlogo igra županova hči Majda, nastopajo pa tudi njen fant Peter in drugi vaščani. Da bi gledališče čim bolj uveljavili, povabijo mestnega kritika Zgago in ga, v upanju na dobro kritiko, ves teden gostijo. Majda se zaljubi v kritika in zapusti Petra. Peter je obupan in med izvedbo predstave se $\mathrm{z}$ Majdo spreta. Direktor ju le s težavo pomiriti, da uspejo izpeljati predstavo do konca. Zgaga o predstavi napiše uničujočo kritiko in hkrati zavrne Majdo. Besni vaščani se maščujejo, Majda pa se vrne $k$ Petru.

\section{Zasedba orkestra}

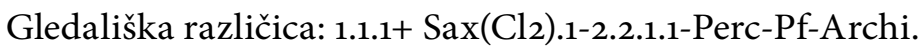

Radiofonska različica: 1.o.1.o.-0.1.1.o-Perc-Pf-harmonij ${ }^{19}$

Delo (gledališka različica) obsega 21 glasbenih točk in je razdeljeno v tri dejanja. Po številki 8 je v partituri previden 15-minutni odmor. 
1. dejanje.

1 - Uvertura (Peter in vaščani); 2 - Allegro comodo (Župan); 3 - Fox (Dama in Direktor); 4 - Angleški valček (Majda); 5 - Slow-fox (Peter); 6 Fox (Špelca in Žan); 7 in 8 - Finale - Andante (Zbor vaščanov)

2. dejanje.

9 - Slow-fox (Zbor vaščanov); 10 - Slow fox (Majda); 11 - Slow fox (Peter); 12 - ponovitev številke 2 (Župan); 13 - Valček (Dama in Direktor); 14 Tango (Peter in Majda); 15 - Fox (Žan in Špelca); 16 - Allegro comodo (Peter, Majda, Župan Špelca)

3. dejanje.

17 - uvod (Direktor in zbor vaščanov); 18 - Allegro molto (Špelca); 19 melodrama (Majda); 20 - reminiscenca (Špelca in Žan); 21 - finale (Peter in zbor vaščanov)

\section{Libreto}

Osnova za libreto je veseloigra Josipa Frana Knafliča »Kmečki teater«, ki ga je Delak priredil za opereto, pri čemer »so dialogi in osnovno dogajanje ostali Knafličevi in je Knaflič operetni aranžman pregledal in 'avtoriziral' «. ${ }^{20} \mathrm{Ker}$ izvirni libreto ni ohranjen niti se ga ne da rekonstruirati na podlagi še obstoječih fragmentov, je mogoče sklepati nanj le posredno. Zagotovo so bili napravljeni določeni posegi v Knafličev tekst, sicer 'avtorizacija' ne bi bila potrebna. Pri tem ne gre le za dodane Jelačinove verze za glasbene točke. Delak pravi:

[...] in če spravimo še mariborsko občinstvo do tega, da bo pri vloženi operni parodiji našlo z nami kontakt in samo sodelovalo $v$ opereti-potem ni vrag, da ne bi uspeli. Da-opera. Tu sva si s Kozino dovolila svojevrstno hudobijo. In ne bo odveč, da to javno priznava. Centralna oseba 'Majde' je gospod direktor, ki pripravlja v slovenskem letovišču za tujski promet važno gledališče 'Kmečki teater'. Sam je napisal libreto, sam ga komponiral, sam režira in dirigira ves svoj obrat. S Kozino sva mu podtaknila na znane operne melodije tekste $v$ slogu naših starih opernih prevodov, pri režiji te scene sem si pa-oslanjajoč se na muziko - dovolil par sicer groteskno po- 
danih, a vendar značilnih koreografskih momentov, ki bodo poznavalce opere in stare šablonske operne režije gotovo spravili v dobro voljo - če niso popolni filistri. ${ }^{21}$

Delak in Kozina sta torej imela ambicije, ki presegajo literarno predlogo, saj sta tekst nadgradila $\mathrm{z}$ aktualno kritiko določene gledališke prakse. S tem se je Majda približala izvornim značilnostim operete, kateri je bila lastna satirična ost. V Majdi se je odrazila kot satiričen pogled na tedanje slovensko podeželje in hkrati parodija na okostenelo odrsko operno prakso.

Igor Grdina je za koncertno izvedbo operete leta 1999 napisal nov libreto. Ob tem je zapisal:

Ne gre za poskus rekonstrukcije izvirnega besedila, ki mi ni bilo dosegljivo niti fragmentirano ( $v$ izvirni partituri so zapisane zgolj posamezne iztočnice), temveč za praktično povsem nov libreto. Tematika in delno tudi motivika je povzeta po Knafličevi 'veseli trodejanki', ki je bila objavljena $v$ revijalni obliki; ker je operetno besedilo samosvoj odrski žanr, navadno prirejanje komedije ni prišlo $v$ poštev. ${ }^{22}$

V Grdinovi verziji so ohranjeni trije različni operetni pari, zmanjšano je število nastopajočih oseb, v libretu pa je skušal tudi ohraniti duha časa nastanka operete.

\section{Glasba}

V pogledu zgradbe kaže Majda tipične operetne značilnosti. Strukturirana je $\mathrm{v}$ treh dejanjih, ki so glede na trajanje $\mathrm{v}$ običajnih razmerjih in s kratkim tretjim dejanjem $\mathrm{z}$ razpletom in glasbenimi reminiscencami. V zgodbi nastopajo, namesto običajnih dveh, tri dvojice, ki po različnih zapletih med ženskim in moškim polom na koncu le pridejo srečno »skupaj«. Pari se, kot je to v opereti običaj, med seboj razlikujejo po karakterju, kar podkrepi glasba. Tudi glasovna zasedba vlog je glede na karakter protagonistov tipična in še bi lahko naštevali.

Pri oblikovanju solističnih vlog se je Kozina držal preverjenih operetnih pravil. Osrednji romantični par je zasnovan za lirski ali mladodramski sopran in lirski tenor, »vihravi« par za tenorja buffo in subreto, pa tudi os-

\section{Ibid.}

22 Grdina, »Majda, opereta v treh dejanjih«, 139. 
tale vloge so glasovno zastavljene po ustaljenem principu. Tessitura nekaterih vlog omogoča različne glasovne zasedbe.

Glasbene točke so povečini popularni in modni plesi iz tridesetih letih prejšnjega stoletja. Prevladujeta standardni različici foxtrota - fox in slow fox, ki sta bili po dveh desetletjih od nastanka tedaj na vrhuncu priljubljenosti. Ne manjkata pa niti tango in angleški valček. Valček (dunajski), ki je kraljeval opereti, je pomaknjen v ozadje. Glasbene točke so povečini grajene standardno. Gre za pesemske oblike s "pravilno « periodično gradnjo, pogosto opremljene $\mathrm{z}$ repeticijami. Od plesnih skladb nekoliko odstopata finala prvega in drugega dejanja. Zaključni prizor prvega dejanja je izrazito razpoloženjska scenska glasba $\mathrm{z}$ uporabo karakterističnega motiva Petrove »tožbe« iz glasbene številke 5. V finalu drugega dejanja, imenovanem »Quodlibet«, je Kozina za potrebe karikiranja tedanje zaprašene operne prakse uporabil znane fragmente iz Traviate, Trubadurja, Rigoletta, Veselih žena windsorskih, Hoffmannovih pripovedk in še od kod. Kot vezivo se skozi delo večkrat pojavi isti motivni material in v zaključnem dejanju tudi običajne reminiscence.

Slog sledi tedanji popularni glasbi. Kozina je Majdo imenoval »jazz opereta - z elementi jazza«. Jazzovski vplivi so kljub takšni oznaki precej zmerni. Odražajo se predvsem v uporabi sinkopiranih ritmov. Kozina je nato orkestrski zvok obarval še s saksofonom in mestoma več pozornosti posvetil tolkalom. Kljub temu je zvok orkestra v osnovi še vedno »romantičen « in daje skupaj z melodiko v nekaterih točkah celo slutiti Kozinovo kasnejšo filmsko glasbo. Orkestracija je nekoliko masivnejša, če jo primerjamo z najbolj popularnimi sodobniki (npr. Paul Abraham) ${ }^{23}$, a je obrtno zelo dobro zastavljena, domiselna in tudi vokalu ustrezna. Solistični deleži so pisani hvaležno z izjemo vloge Špelce, pri kateri je glede na običajne karakteristike ustreznega tipa glasu precej izpostavljena spodnja sopranska lega in je zato v gledališki praksi vlogo nekoliko težje adekvatno zasesti. Melodije so sveže, naravno tekoče, vzdušje je skladno s tedanjimi modnimi tokovi v popularni glasbi, vendar invencija zastane pred zadnjo oviro, pred tisto točko preboja, ki ji v žargonu pravimo »hit«, zadetek v polno; torej »šlager«, ki zaznamuje delo in mu lahko zagotovi trajno odrsko življenje.

23 Kozina je orkestracijo v Majdi sam označil kot "preveč starinsko, sploh preveč kalmanovsko.« Pismo Marjana Kozine domačim, 12. oktober 1935. Prepis Jurija Kozine (pri Igorju Grdini). 
Majda z uporabo elementov jazza na Slovenskem v tistem času ni bila kaka revolucionarna novost. Že dve leti pred tem so npr. v Ljubljani uprizorili Gregorčevo jazz opereto Erika, predvsem pa so tako v Ljubljani kot v Mariboru uprizarjali uspešnice Paula Abrahama, ki so slogovno precej drznejše, $\mathrm{z}$ močnejšimi primesmi jazza in manj masivnim orkestrskim zvokom. ${ }^{24}$ Sodeč po kritikah se je uprizoritev Majde bližala glasbeni reviji, ${ }^{25}$ kar je bil tedaj tudi sicer trend razvoja operete.

\section{Izvedba in sprejem}

Opereta je bila premierno izvedena 24. 11. $1935 \mathrm{v}$ mariborskem gledališču. Kozini, ki je predstavo tudi dirigiral, in Delaku sta se pridružila še Ljubivoj Ravnikar kot scenograf in Anton Harastovič kot koreograf. V vlogah so nastopili nekateri vodilni pevci iz gledališča kot Pavla Udovič v vlogi Majde, Belizar Sancin v vlogi Nandeta, Pavle Kovič kot Župan, zraven pa še številni dramski igralci, nekateri zasedeni tudi v pevskih vlogah. ${ }^{26}$

Uprizoritev je bila deležna za tiste čase veliko publicitete in je tudi pri občinstvu dobro uspela. Že pred premiero so časopisi najavili uprizoritev nove slovenske operete. ${ }^{27}$ Mariborski Večernik je objavil kratek intervju z Delakom in Kozino. Isti pogovor s Kozino je objavilo tudi Jutro. Izvedli so deset predstav, kar pa ni bilo največje število izvedb operete slovenskega avtorja v mariborskem gledališču.

24 Pred postavitvijo Majde so bile v mariborskem in ljubljanskem gledališču uprizorjene Abrahamove uspešnice Viktorija in njen huzar, Havajska roža in Ples $v$ Savoyu. c., »Kulturni pregled. Krst nove slovenske operete v Mariboru«, Jutro 16, št. 277 (29. november 1935): 7, http://www.dlib.si/?URN=URN:NBN:SI:doc-ALZZS8YF.

26 Zasedba vlog na premieri: Romantična dama - Ema Starc; Župan - Pavle Kovič; Majda, njegova hči - Pavla Udovič; Gospod direktor - Danilo Gorinšek; Janko Rešetar, časnikar - Edo Grom; Žanek, športnik - Anton Harastovi; Nande - Belizar Sancin; Špelca, pastirica - Elza Barbič; Šepav možic - Milan Košič; Stara ženica Mileva Zakrajšek; I. novinar - Just Košuta; II. Novinar - Franjo Blaž; Novinarka - Slava Gorinšek; Filmski operater - Slavko Starc; Napovedovalec radijske postaje - Rado Nakrst; Fotograf - Edo Verdonik; Spremljevalka romantične žene - Danica Savin; Potni maršal romantične dame - Milan Košič; letoviščarji, turisti, kmetje, lovci, igralci »Kmečkega teatra«.

27 Predstavo so najavili: Jutro 24. 11. 1935 (c. »Krst nove operete v Mariboru«, 4), Večernik 23. 11. 1935 (c., »Mariborske in okoliške novice. Nova slovenska opereta (iz razgovora z avtorjem prof. Kozino «, Mariborski Večernik »Jutra« 16, št. 267 (23. november 1935): 4, http://www.dlib.si/?URN=URN:NBN:SI:doc-W9CCVRPE), Mariborer Zeitung 24. 11. 1935 (Anon., »Kultur-Chronik. Uraufführung im Mariborer Theater. 'Majda', Operette in drei Akten / Die neue schwungvolle Revue-Jazz-Operette von Marjan Kozina", Mariborer Zeitung 75, št. 268 (24. november 1935): 6, http://www. dlib.si/?URN=URN:NBN:SI:doc-WCFRK1IX). 
Kritiški odzivi so bili zvečine dobri. V Jutru je kritik poudaril glasbo, kjer se združuje prijetna ariozna melodioznost s solidno jazzno zamislijo. Tako je ustvaril Kozina nekakšno novo obliko sodobne operete, kjer se vzlic precejšnji odmaknjenosti od tradicionalne operetne muzike upoštevajo činitelji blagodoneče melodike ter se hkrati dajejo partnemu zasnutku rahli jazzni poudarki. Tako je vznikla opereta veselo zanosne, tople in prijetne glasbe, ki ne predstavlja niti najmanj kakšnih poiskusov reševanja kompliciranejših glasbenih problemov, ki sodijo $v$ druge skladbe, nikakor pa ne $v$ operetne. Nič ni zaradi tega čudnega, ako je ta glasba popolnoma prodrla ter toplo prevzela občinstvo, ki ga je bilo v gledališču toliko, kakor zlepa še ne doslej..$^{28}$

Kritik opozori na določene šibkosti libreta in ugotavlja, da »izdatnejša, prvotno nameravana korektura ne bi bila napak«. V nadaljevanju pohvali režijo in uprizoritev kot celoto ter vse pevske in igralske dosežke. Kritik zaključi:

Kozinova 'Majda' je solidna in svetla postavka na obzorju naše odrske tvornosti. Nedvomno pojde, sodeč po mariborskem zmagoslavnem uspehu, tudi na druge odre. ${ }^{29}$

Kritika v konservativnem Slovencu je bila, pričakovano, manj ugodna. Kritik izpostavlja dolgoveznost nekaterih prizorov, pohvalno se izrazi o Delakovem deležu, »ker sicer $v$ delu samem ni nobene vsebinske prilike za poglobljeno igro«. Glasbi ni bil naklonjen:

Glasbeno pomeni delo za nas malo. Muzika je lahka, vsebinsko prazna, giblje se $v$ načinu jazza, tudi posamezne arije imajo značaj moderne plesne glasbe. Človeku se vsiljuje misel, da bi bilo bolje posvetiti mlade stvarilne moči vzvišenejšim ciljem, ki bi slovenski glasbeni umetnosti in literaturi dali tudi neko zares umetniško vrednoto. Je pa $v$ opereti dovolj muzikalnega čuta in sveže melodioznosti, ki bosta za slehernega poslušalca prijetno in ugodno vplivali. $^{30}$

Uspeh uprizoritve pripisuje prvenstveno režiji in igralskim dosežkom. 
Do libreta je bil kritičen tudi ocenjevalec v Glasu naroda. ${ }^{31}$ Nemški Morgenblatt pa je pohvalil Kozino, ker je glasba »dobra, zanosna in prepletena $z$ modernizmi, ki so zaradi skladateljevega tehničnega znanja in umetniške domiselnosti kar najsrečneje izraženi «. ${ }^{32}$

Ciril Cvetko navaja, da si je Kozina, tudi s pomočjo Delakovih zvez, prizadeval z Majdo prodreti tudi na druge odre, vendar s tem ni uspel..$^{33} \mathrm{~S}$ tem je bil povezan tudi njegov obisk na Dunaju oktobra $1935 .^{34}$

Opereto Majda z besedilom Igorja Grdine so koncertno izvedli 19. aprila $2001 \mathrm{v}$ Novem mestu. Izvajalci so bili Novomeški simfonični orkester pod vodstvom dirigenta Zdravka Hribarja, ki je za to priložnost tudi uredil partituro in orkestrski material operete, ter solisti Marjetka Podgoršek Horžen kot Majda, Ursula Langmayr kot Špelca, Irena Akweley Yebuah kot Romantična dama, Saša Ivaci kot Župan, Robert Vrčon kot Direktor Ferdo, Marjan Trček kot Peter in Milivoj Juras kot Žan. Izvedba je doživela topel sprejem.

\section{Sklep}

Majda Marjana Kozine sodi med najboljše slovenske stvaritve na področju operete. Iz dela je razvidno predvsem Kozinovo zelo kakovostno obrtno znanje, kakršnega drugi slovenski skladatelji te zvrsti niso imeli, kar je opazila tudi kritika. Kozinova melodična invencija je v okviru žanra na visoki ravni, vendar brez uspešnice, ki bi delo zaznamovala. Prav to pa je eden od nujnih pogojev glasbeno gledaliških del lažje zvrsti za usidranje v železnem repertoarju. Vsekakor si zasluži Majda ponovno postavitev na gledališki oder, ob, seveda, izredno domiselni režijski zasnovi in dobri igralsko pevski zasedbi.

Marjan Kozina je s svojo glasbeno invencijo, odličnim znanjem skladateljske obrti ter izrazitim smislom za gledališče $\mathrm{z}$ opero Ekvinokcij in z opereto Majda ustvaril deli, ki sodi vsako v svoji zvrsti v vrh slovenskih glasbeno gledaliških stvaritev.

\footnotetext{
31 Cvetko, Marjan Kozina, 84.

32 Ibid., 86.

33 Ibid., $80-1$ in 87.

34 Grdina, »Kozinovo Dekle z Jadrana«, 40.
} 


\section{Bibliografija}

Anon. »Kultur-Chronik. Uraufführung im Mariborer Theater. ,Majda', Operette in drei Akten / Die neue schwungvolle Revue-Jazz-Operette von Marian Kozina«. Mariborer Zeitung 75, št. 268 (24. november 1935): 6. http://www.dlib.si/?URN=URN:NBN:SI:doc-WCFRK1IX.

Bb. »Mariborsko gledališče: Nova slovenska opereta 'Majda'«. Slovenec 58, 276a (30. november 1935): 5. http://www.dlib.si/?URN=URN:NBN:SI: doc-MZVWZHNQ.

c. »Mariborske in okoliške novice. Nova slovenska opereta (iz razgovora $\mathrm{z}$ avtorjem prof. Kozino«. Mariborski Večernik»Jutra« 16, št. 267 (23. november 1935): 4. http://www.dlib.si/?URN=URN:NBN:SI:doc-W9CCVRPE.

c. »Krst nove operete v Mariboru«. Jutro 16, št. 273 (24. november 1935): 4. http:// www.dlib.si/?URN=URN:NBN:SI:doc-QNTN2ZDD.

c. »Kulturni pregled. Krst nove slovenske operete v Mariboru«. Jutro 16, št. 277 (29. november 1935): 7. http://www.dlib. si/?URN=URN:NBN:SI:doc-ALZZS8YF.

Cszáky, Moritz. Ideologija operete in dunajska moderna. Ljubljana: Inštitut za civilizacijo in kulturo, zbirka Vita Activa, 2001.

Cvetko, Ciril. Marjan Kozina. Ljubljana: Partizanska knjiga, 1983.

Delak, F. »Majda, ti moja sreča vsa ... Pred premiero v mariborskem Narodnem gledališču«. Mariborski Večernik »uutra» 16, št. 267 (23. november 1935): 6. http://www.dlib.si/?URN=URN:NBN:SI:doc-W9CCVRPE.

Grdina, Igor. »Majda, opereta v treh dejanjih«. V Marjan Kozina, 1907-1966: Mednarodni simpozij o Marjanu Kozini ob koncertni izvedbi operete Majda, urednik Primož Kuret, 137-58. Novo mesto: Glasbena šola Marjana Kozine, 2002.

Grdina, Igor. »Kozinovo Dekle z Jadrana«. V Marjan Kozina: 2. mednarodni simpozij o Marjanu kozini ob 1oo-letnici rojstva, urednik Primož Kuret, 35-49. Novo mesto: Glasbena šola Marjana Kozine, 2007.

Kozina, Marjan. Majda, opereta v treh dejanjih. Besedilo Igor Grdina. Redakcija Zdravko Hribar. Print. Zgodovinski arhiv Ljubljana, Enota za Dolenjsko in Belo krajino v Novem mestu, arhivska oznaka 133334.

Kozina, Marjan. Majda, Opereta. Partitura. Zgodovinski arhiv Ljubljana, Enota za Dolenjsko in Belo krajino v Novem mestu, arhivska oznaka 133334.

Kozina, Marjan. Majda, Operette. Klavirauszug. Klavirski izvleček. Rokopis. Zgodovinski arhiv Ljubljana, Enota za Dolenjsko in Belo krajino v Novem mestu, arhivska oznaka 133334 . 
Kozina, Marjan. Majda. Orkestrski material radiofonske izvedbe. Rokopis. Zgodovinski arhiv Ljubljana, Enota za Dolenjsko in Belo krajino v Novem mestu, arhivska oznaka 133334 .

Kozina, Marjan. Pismo Marjana Kozine domačim. Prepis Jurija Kozine. 12. oktober 1935. Hrani Igor Grdina.

Kozina, Marjan. Pismo Marjana Kozine Petru Bingulcu ob pripravah na uprizoritev »Ekvinokcija« v Novem Sadu. Prepis Jurija Kozine. Piran, 12. oktober 1963 . Hrani avtor.

Kuret, Primož. »Oči stran od lepote ...«. V Marjan Kozina, 19o7-1966: Mednarodni simpozij o Marjanu Kozini ob koncertni izvedbi operete Majda, urednik Primož Kuret, 123-30. Novo mesto: Glasbena šola Marjana Kozine, 2002.

Kuret, Primož. »Marjan Kozina: Prispevek za biografijo«. V Muzikološki zbornik - Musicological Annual VII, urednik Dragotin Cvetko, 90-101. Ljubljana: Oddelek za muzikologijo filozofske fakultete, 1971. https://revije. ff.uni-lj.si/MuzikoloskiZbornik/article/download/4772/4475/.

Majda. Plakat Narodnega gledališča v Mariboru. Zgodovinski arhiv Ljubljana, Enota za Dolenjsko in Belo krajino v Novem mestu, arhivska oznaka 3288 8.2.

»Marjan Kozina: Majda, koncertna izvedba operete«. RTV Slovenija. https://4d. rtvslo.si/arhiv/koncerti-kulturno-umetniski-program/174556603.

Moravec, Dušan, ed. Repertoar slovenskih gledališč 1867-1967. Ljubljana: Slovenski gledališki muzej, 1967. 